\title{
Design of PID Filter Controller with Genetic Algorithm for Mimo System in Modern Power Generation
}

\author{
Anitha Mary. X ${ }^{1}$ L. Sivakumar ${ }^{2}$ \& J.Jayakumar ${ }^{3}$ \\ ${ }^{1}$ Research scholar, Department of Electronics and Instrumentation Engineering, Karunya University, Coimbatore, \\ India \\ ${ }^{2}$ Vice Principal and Dean R\&D, Sri Krishna College of Engineering and Technology, Coimbatore and Formerly \\ General Manager, Corporate R\&D, Bharath Heavy Electricals Limited, Hyderabad, India \\ ${ }^{3}$ Associate professor, Department of Electrical and Electronics Engineering, Karunya University, Coimbatore, \\ India \\ Correspondence: Anitha Mary. X, Research scholar, Department of Electronics and Instrumentation Engineering, \\ Karunya University, Coimbatore, India. E-mail: anithajohnson2003@gmail.com
}

Received: July 8, 2014 Accepted: July 24, 2014 Online Published: September 1, 2014

doi:10.5539/mas.v8n5p186 URL: http://dx.doi.org/10.5539/mas.v8n5p186

\begin{abstract}
In this work, a new technique based on Genetic Algorithm for designing multivariable PID filter controller has been developed and applied to gasifier control of ALSTOM benchmark challenge II. The coal gasifier is the main component in Modern power generation. Coal gasifier involves several performance and robustness requirements in addition to actuator constraints under three operating loads (no-load, 50\% and 100\% load). The proposed GA optimises the tuning parameters of PID constants in terms of robustness and performance. The optimised controller meets all design objectives under all operating conditions. Robustness of the controller is tested for step and sinusoidal pressure disturbances applied at the inlet of throttle valve along with increase and decrease of calorific value of fuel fed-in (coal). Simulation results obtained confirmed the superiority of proposed technique for gasifier problems.
\end{abstract}

Keywords: ALSTOM gasifier, MIMO system, gasifier performance, gasifier control, PIDF controller, Genetic Algorithm

\section{Introduction}

Coal gasifier plays an important part in clean coal power generation. It converts coal into syngas under high temperature and pressure. Control of gasifier becomes vital in producing syngas with higher efficiency. In this context, ALSTOM, the UK power generation centre, posed the benchmark challenge II to design controller for gasifier that incorporates pressure disturbance test as well as coal quality variation test. The MATLAB SIMULINK model (Dixon et. al., 2006) given by ALSTOM controller design should satisfy the design objective for output magnitude and rate of constraints at the input under three operating loads (no-load, $50 \%$ and $100 \%$ load). In this paper, optimised Proportional Integral and Derivative filer controller is designed. Even though, many optimisation algorithms exist, Genetic Algorithm is mainly used to solve global optimization problems existing in power systems. In spite of its high computation time, GA based techniques are highly preferred, because GA works with population of solutions rather than with single solution. In this paper, the parameters of Proportional Integral Derivative controller with filter approach are optimised using Genetic Algorithm and multiobjective problem existing in gasifier is converted into single optimisation problem and can be taken as objective function.

\subsection{Gasifier Plant}

Gasifier is a chemical reactor with five inputs (coal flow, air flow, steam flow, limestone flow and char extraction flow) and four outputs (pressure, temperature and calorific value of syngas and bedmass). Coal reacts with steam and air to produce low calorific value fuel gas and char. Limestone is added to capture sulphur content in the coal. Oxygen in the fluidising air combine with carbon present in char to form carbon monoxide and carbon dioxide. Though several endothermic and exothermic equations occur, the main equations involved in gasifier are

$$
\mathrm{C}+\mathrm{O}_{2} \longrightarrow \mathrm{CO}_{2}
$$


Equations 1 and 2 are exothermic gasification.

$$
\mathrm{C}+1 / 2 \mathrm{O}_{2} \longrightarrow \mathrm{CO}
$$

The carbon-dioxide reacts more with carbon to form carbon-monoxide. Also steam reacts

with carbon to form carbon-monoxide and hydrogen.

Equations 3 and 4 are endothermic reactions.

$$
\stackrel{\mathrm{C}+\mathrm{CO} 2}{\mathrm{C}+\mathrm{H}_{2} \mathrm{O}} \longrightarrow \begin{gathered}
2 \mathrm{CO} \\
\mathrm{CO}+\mathrm{H} 2 \mathrm{O}
\end{gathered}
$$

The un-reacted char is added to the bed, which is maintained at a constant height and will be removed periodically. The fuel gas is filtered and combusted in a gas turbine to generate electricity. As a result, one of the disturbances is a change of downstream pressure (Pressure test) at the gas turbine throttle valve. The coal quality of syngas also affects the power generation (model error test). The objective of benchmark challenge II is to control the gasifier system with step and sinusoidal pressure disturbances (Psink) with increased and decreased coal quality variations. The objective is to control the gasifier maintaining the steady state value of output variable within the limit as well as maintaining the rate of constraints at the input as shown in table 1 and 2 . A group of authors attempted different methods such as Model predictive control (Al Seyab et. al., 2006), Ho (Gatley S.L, 2006), optimal PI controllers (Gatley et. al., 2004, Simm et. al., 2006, Koteeswaran et. al., 2014, Xue Y et. al., 2010), Fuzzy gain scheduled controller (Yong wang, et. al., 2009) and suggested suitable controllers. While these methods have provided desirable solutions, certain segments remained unattempted especially with respect to coal quality variations as shown in table 3.

Table 1. Output variables with allowable limits

\begin{tabular}{lcccc}
\hline Output variables & $\begin{array}{l}\text { Steady state value } \\
\text { for 100\% load }\end{array}$ & $\begin{array}{l}\text { Steady state value } \\
\text { for 50\% load }\end{array}$ & $\begin{array}{l}\text { Steady state value } \\
\text { for 0\% load }\end{array}$ & Limits \\
\hline Calorific value of syngas (CVGAS) & 4.36 & 4.49 & 4.71 & \pm 0.01 \\
in MJ/Kg & & & & 10000 \\
Bed mass(MASS) in Kg & 10000 & 10000 & 11.2 & \pm 500 \\
Fuel gas pressure (PGAS) in bar & 20.1 & 15.5 & 1115.1 & \pm 0.1 \\
Fuel gas temperature (TGAS) in K & 1223.1 & 1181.1 & \pm 1 \\
\hline
\end{tabular}

Table 2. Input variables with allowable limits

\begin{tabular}{lccc}
\hline Input variable & Maximum value in $\mathrm{Kg} / \mathrm{s}$ & Minimum value in $\mathrm{Kg} / \mathrm{s}$ & Peak rate in $\mathrm{kg} / \mathrm{s}^{2}$ \\
\hline Coal flow (WCOL) & 10 & 0 & 0.2 \\
Air flow (WAIR) & 20 & 0 & 1.0 \\
Steam flow (WSTM) & 6 & 0 & 1.0 \\
Char Extraction (WCHAR) & 3.5 & 0 & 0.2 \\
\hline
\end{tabular}

\begin{tabular}{|c|c|c|c|}
\hline S.No. & Authors & Controller methods & $\begin{array}{l}\text { Change in calorific value with a wide } \\
\text { band of } \pm 18 \% \text { at three operating } \\
\text { loads- } 0 \%, 50 \% \text { and } 100 \% \text { (Coal } \\
\text { quality test) and pressure } \\
\text { disturbance test }\end{array}$ \\
\hline 1 & $\begin{array}{l}\text { Anthony } \\
\text { Simms et. al., }\end{array}$ & Multi objective optimization ap & $\begin{array}{l}\text { Results are not shown for coal quality } \\
\text { test. Results are available only for } \\
\text { pressure disturbance test. }\end{array}$ \\
\hline 2. & $\begin{array}{l}\text { Sarah } \\
\text { Gatleyet. al., }\end{array}$ & H-infinity design approach & $\begin{array}{l}\text { Results are not shown for coal quality } \\
\text { test. Results are available only for } \\
\text { pressure disturbance test. }\end{array}$ \\
\hline 3. & Wilson et. al., & $\begin{array}{l}\text { state estimators to improve on the base } \\
\text { line performance }\end{array}$ & $\begin{array}{l}\text { Results shown for }+18 \% \text { coal quality } \\
\text { variations }\end{array}$ \\
\hline 4. & Y. Cao et. al., & Model Predictive controller & $\begin{array}{l}\text { Results shown for } 100 \% \text { load } \\
\text { exceeding the specified output limit }\end{array}$ \\
\hline
\end{tabular}

Table 3. Various controller methods for ALSTOM benchmark challenge II 


\begin{tabular}{llll}
\hline 5 & Yong Wang & $\begin{array}{l}\text { Study on Fuzzy Gain-Scheduled } \\
\text { Multiple Mode Predictive } \\
\text { Control of ALSTOM } \\
\text { Gasifier Problem }\end{array}$ & $\begin{array}{l}\text { Results not shown for coal quality test. } \\
\text { Results are available only for pressure } \\
\text { disturbance test. }\end{array}$ \\
$6 \quad$ & $\begin{array}{l}\text { Results shown for }+18 \% \text { to }-7 \% \text { for } \\
\text { R.Kotteswaran } \\
\text { L.Sivakumar }\end{array}$ & $\begin{array}{l}\text { Performance evaluation of optimal PI } \\
\text { controller for ALSTOM gasifier during } \\
\text { coal quality variations }\end{array}$ & \begin{tabular}{l} 
sinusoidal disturbance at $0 \%$ load . \\
\hline
\end{tabular} \\
\hline
\end{tabular}

\section{Proposed Genetic Algorithm based PID Filter Controller}

PID controllers are widely used for complex chemical processes and engineering systems.

The structure of PID controller is given by

$$
\mathrm{C}(\mathrm{s})=\mathrm{Kp}\left(1+\frac{1}{s T_{i}}+\mathrm{T}_{\mathrm{d}} \mathrm{s}\right)=\mathrm{P}\left(1+\mathrm{I}\left(\frac{1}{\mathrm{~s}}\right)+\mathrm{Ds}\right)
$$

However, one of the most common problems associated with PID is with the synthesis of derivative action. The ideal derivative has very high gain and susceptible for noise accentuation (Aström et. al., 1995). Hence the authors have chosen PID filter controller whose derivative action is represented as $\mathrm{D}=\frac{K_{d} s}{1+s T_{f}}$. Here $\mathrm{T}_{\mathrm{f}}$ is called filtering time The transfer function of a PID controller with a filtered derivative is give in equation (6)

$$
\mathrm{C}(\mathrm{s})=\mathrm{Kp}\left(1+\frac{1}{s T_{i}}+\frac{s T_{d}}{1+s \frac{T d}{N}}\right)=\mathrm{P}\left(1+\mathrm{I}\left(\frac{1}{s}\right)+\mathrm{D}\left(\frac{N_{s}}{s+N}\right)\right)
$$

and are schematically shown in Figure 1.

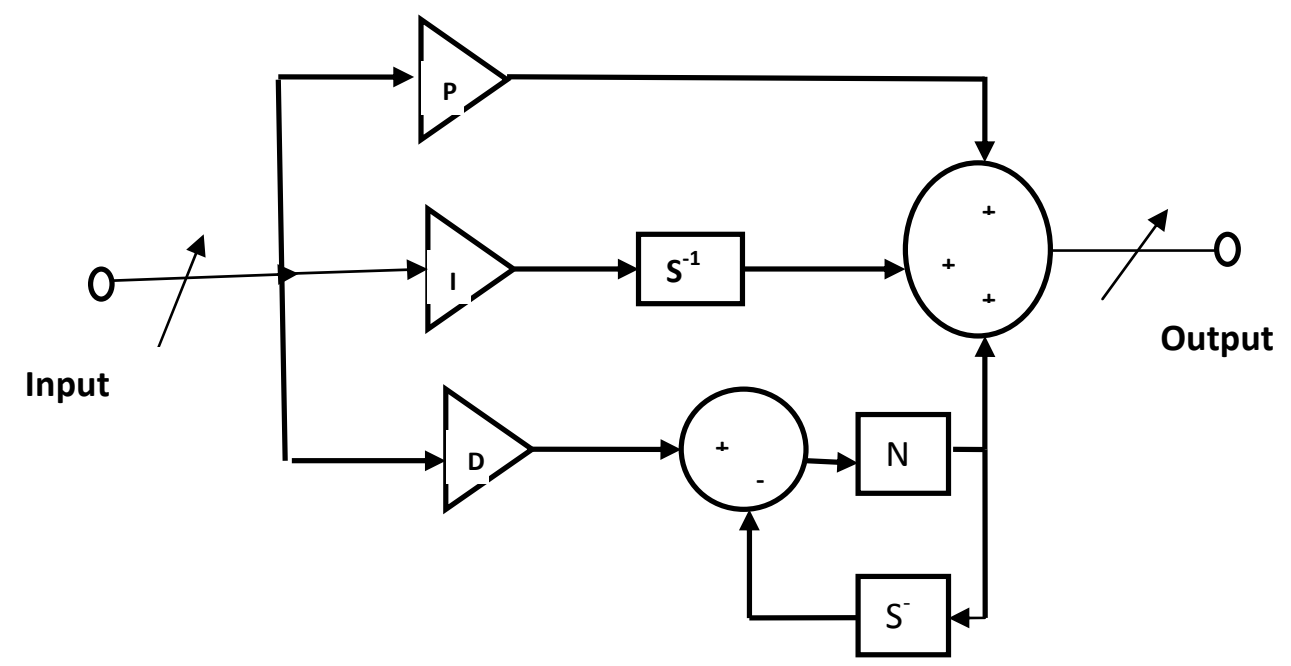

Figure 1. Schematic for PID filter controller

\subsection{Problem Formulation and Implementation}

PID tuning can be performed using techniques like empirical methods such as Zeigler Nicholas method (Aström et. al.,1995), analytical methods like root locus technique (Blasco et. al., 2000) and optimisation methods such as Lopez and Ciancone methods (Marlin et. al., 1995). The PID values obtained through these methods can be applied to a system operating in an particular operating point. When the system is operating under different operating zones, genetic algorithms can be used to tune PID parameters taking all non linearities and process characteristics into account.

Genetic Algorithms are the optimisation techniques which apply the law of natural selection to achieve polulation in a search space (Deepa et. al., 2009). The search space is the objective function. They use probalisitic transistion method to obtain population of solution called individuals or chromosomes that evolve iteratively. Each iteration is called generation. 


\subsection{Objective Function for Pressure and Coal Quality Disturbance}

For the proposed PID filter controller, step disturbance in Psink is applied to closed loop system and IAE (Integral Absolute errors) are calculated for over 300 seconds. The objective function for step and sinusoidal disturbance in Psink are given in equations (7) and (8).

$$
\begin{gathered}
\mathrm{f}_{1}(\mathrm{x})_{\text {step }}=\sum_{j=1}^{3} \sum_{i=1}^{4} \int_{0}^{300}\left|y_{i s p}^{j}(\mathrm{t})-y_{i}^{j}(\mathrm{t})\right| \\
\mathrm{f}_{2}(\mathrm{x})_{\text {sine }}=\sum_{j=1}^{3} \sum_{i=1}^{4} \int_{0}^{300}\left|y_{i s p}^{j}(\mathrm{t})-y_{j}^{j}(\mathrm{t})\right|
\end{gathered}
$$

similarly the objective function for coal quality change is given in equation (9).

$$
\mathrm{f}_{3}(\mathrm{x})_{\mathrm{CV} \text { of coal }}=\sum_{j=1}^{3} \sum_{i=1}^{4} \int_{0}^{300}\left|y_{i s p}^{j}(\mathrm{t})-y_{i}^{j}(\mathrm{t})\right|
$$

where $\mathrm{fl}(\mathrm{x})$ step is the objective function for step disturbance of -0.2 bar applied at Psink

$\mathrm{f} 2(\mathrm{x})$ sine is the objective function of sinusoidal disturbance of amplitude 0.2 bar and $0.04 \mathrm{~Hz}$ frequency applied at Psink. $\mathrm{f} 3(\mathrm{x}) \mathrm{cv}$ of coal is the objective function for disturbance at fuel fed-in.

yjisp ( $t)$ is the steady state value for output number $i$ at operating load.

$\mathrm{i}=1$ means $\mathrm{CV}$ of syngas; $\mathrm{i}=2$ means bedmass output; $\mathrm{i}=3$ means pressure output of the syngas; $\mathrm{i}=4$ means temperature output for syngas; also $\mathrm{j}=1$ means $100 \%$ load; $\mathrm{j}=2$ means $50 \%$ load and $\mathrm{j}=3$ means $0 \%$ load.

yij $(t)=$ measured output value at the three operating loads.

$$
\mathrm{D}(\mathrm{x})=\mathrm{f} 1(\mathrm{x})_{\text {step }}+\mathrm{f} 2(\mathrm{x})_{\text {sine }}+\mathrm{f} 3(\mathrm{x})_{\mathrm{CV} \text { of coal }} \text { is the fitness value. }
$$

The objective is to minimise $\mathrm{D}(\mathrm{x})$

\subsection{Objective Function for Output Constraints}

When the disturbances are applied, the controller must be tuned in such a way that output limits should not exceed.

$$
\begin{aligned}
& \mathrm{C}_{\text {step }}=\frac{\operatorname{maxmax}_{t}\left\|y_{t}^{j}-\gamma_{t g p}^{j}\right\|}{D_{t}}
\end{aligned}
$$

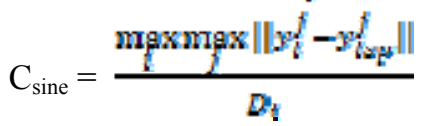

where $y_{i}^{j}=$ measured variable for output $\mathrm{i}$ at operating point $\mathrm{j}$

$y_{i s p}^{1}=$ steady state value for output $\mathrm{i}$ at operating point $\mathrm{j}$.

$\mathrm{Di}=$ allowable deviation of output $\mathrm{i}$

Combining equations (10) and (11), the output objective function is given by

$$
\mathrm{O}=\max (\text { Cstep, Csine ) }
$$

Therefore, the overall objective function is to minimise $\mathbf{D}(\mathbf{x})$ if $\mathbf{O}<\mathbf{1}$.

The procedure for optimising PID filter controller with genetic algorithm is given below:

1. The PID tuning parameters (P,I,D,N) must be encoded in real numbers or vectors or binary strings

2. Population size and limits are noted

3. Normalised Geometric selection is applied to select any random values of parameters based on fitness value.

4. Reproduce the selected parameters to get optimised solution.

5. Arithmetic crossover and uniform mutation are performed to alter the parameters to optimised values.

6. Calculate the fitness value $\mathrm{D}(\mathrm{x})$ for each iteration

7. Repeat steps $8-10$ for ' $n$ ' off springs

8. Using fitness function, find value of error in the Generation.

9. The parameters with highest fitness value are chosen as the final parameter values.

10. If the obtained values are not up to the mark, repeat step 2 
The flow chart for GA based PID tuning is shown in Figure 2 and tuning parameters obtained by proposed and other methods are given in Table 4.

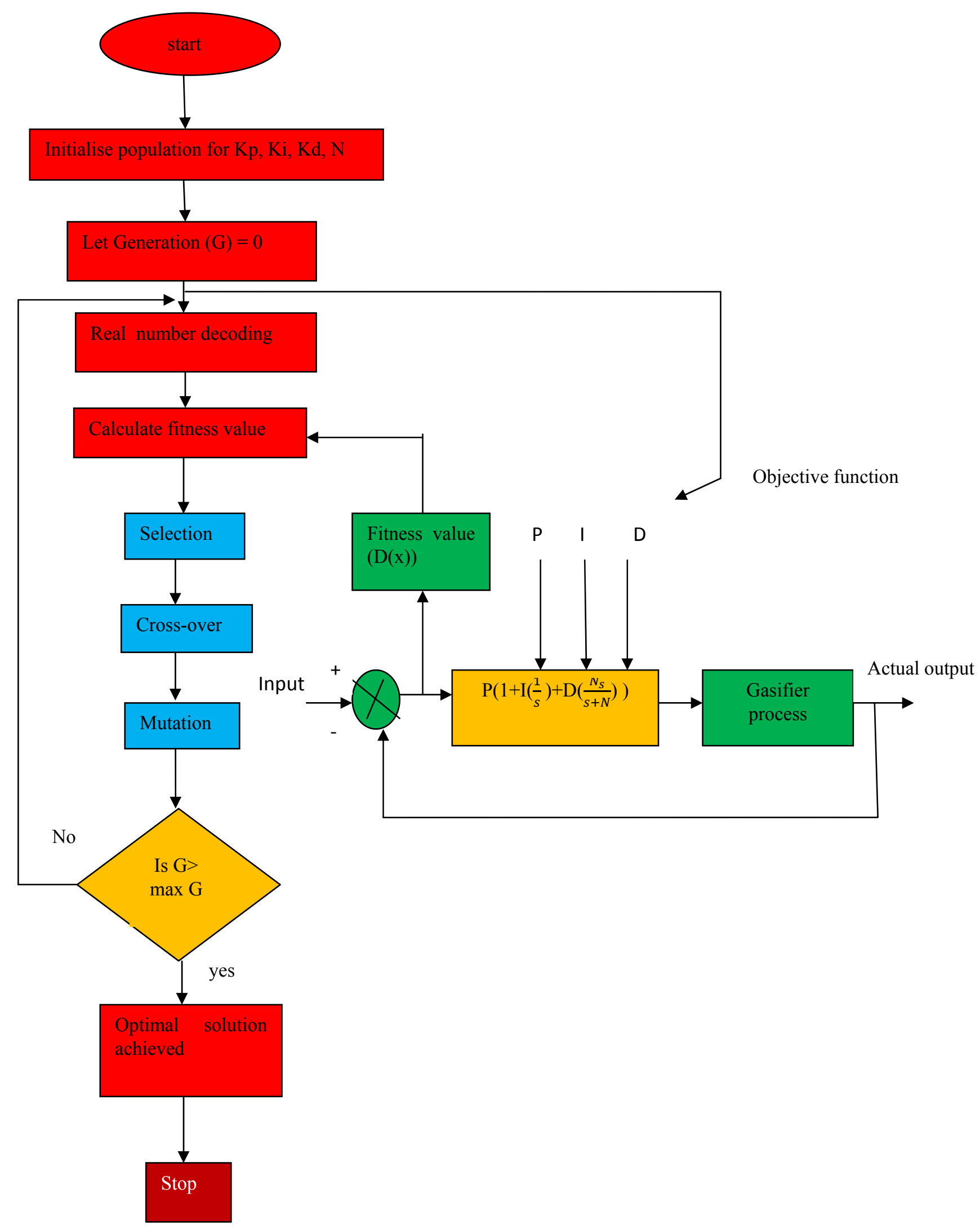

Figure 2. Flow chart for PID tuning using Genetic Algorithm 
Table 4. Tuning parameters by various controller methods

\begin{tabular}{|c|c|c|c|c|c|}
\hline Parameter & $\begin{array}{c}\text { Baseline } \\
\text { PI[Dixon } \\
\text { 2006] }\end{array}$ & $\begin{array}{c}\text { Multi objective } \\
\text { PI controller } \\
\text { [Xue et. al., } \\
2010] \\
\end{array}$ & $\begin{array}{c}\text { Optimal PI } \\
\text { [Kooteeswaran } \\
\text { et. al., 2014] }\end{array}$ & $\begin{array}{c}\text { Multivariable } \\
\text { PID [Farag } \\
\text { 2006] }\end{array}$ & $\begin{array}{c}\text { Proposed GA based PIDF } \\
\text { controller }\end{array}$ \\
\hline CV_Kp & $\begin{array}{l}-0.1226 \mathrm{e}- \\
03\end{array}$ & -0.016972 & $-0.2937 \mathrm{e}-03$ & 0.000044 & -0.002098 \\
\hline CV_Ki & $0.80 \mathrm{e}-03$ & -0.024813 & $0.747 \mathrm{e}-03$ & 0.000068 & 0.000362 \\
\hline CV_Kd & - & - & - & 0 & $\mathrm{~N}=100$ \\
\hline BM_Kp & 0.145070 & 0.18498 & 0.227116 & -0.000367 & 0.000260 \\
\hline BM_Ki & 1.032797 & 1.741 & 1.857655 & -0.000113 & 0.000147 \\
\hline BM-Kd & - & - & - & 0 & $0.2163021 \mathrm{~N}=100$ \\
\hline Pr_Kp & $0.201 \mathrm{e}-03$ & 0.0003055 & $0.1558 \mathrm{e}-03$ & $1.16 \mathrm{e}-05$ & 0.000189 \\
\hline Pr_Ki & $0.656 \mathrm{e}-04$ & 0.00001077 & $0.51 \mathrm{e}-04$ & 0.000118 & 0.000011 \\
\hline Pr_Kd & - & - & - & 0.00026 & 0.00001 \\
\hline Tg_Kp & 1.701288 & 2.2825 & 1.692696 & $2.622 \mathrm{e}-02$ & 1.724918 \\
\hline Tg_Ki & 0.009479 & 0.097237 & 0.009555 & 0.3881 & 0.009927 \\
\hline $\mathrm{Tg} \mathrm{Kd}$ & - & - & - & 0.512 & $0.151923 \mathrm{~N}=0.001574$ \\
\hline
\end{tabular}

\section{Simulation Results and Discussion}

The performance of gasifier during coal quality along with step and sinusoidal disturbance in PSINK is of prime concern according to challenge II. Coal quality is allowed to change incrementally within the range $\pm 18 \%$ with respect to design value of the coal, and the transient performance of the gasifier output variables are monitored using MATLAB/ SIMULINK simulation tools. A step disturbance of -0.2 bar from the steady value of Psink and sinusoidal disturbance of $0.2 \mathrm{bar}$ as amplitude and $0.04 \mathrm{~Hz}$ are applied along with $\pm 18 \%$ calorific value of coal. Further, an auto tuning option has been chosen.

The simulation responses pertaining to the change in calorific value of the fuel along with step and sinusoidal disturbance in Psink are shown in figures 3 -14. For the purpose of analysis, the input and output limits within which the input and output variables should lie during transient region are shown in Table 1 and 2.

\subsection{Step Disturbance at Psink Coupled with $\pm 18 \%$ CV of Coal Variation}

Figure 3 shows that the output variables (pressure, temperature and calorific value of the syngas) are reaching the respective set point values $(11.2 \mathrm{bar}, 1115.1 \mathrm{~K}$ and $4.71 \mathrm{MJ} / \mathrm{Kg}$ ) corresponding to $0 \%$ load. Figure 4 shows that the input variable flow rates for coal air and steam are also within the allowable limits corresponding to $0 \%$ load. Similar figures for input and output variables corresponding to $50 \%$ and $100 \%$ loads are shown in Figure 48. It is observed that Coal flow rates are deviating from the allowable band at $100 \%$ load for coal quality variation in the negative direction.

\subsection{Sinusoidal Disturbance Coupled with Coal Quality Variations}

Figure 9 shows that the output variables (pressure, temperature and calorific value of the syngas) are reaching the respective set point values $(20 \mathrm{bar}, 1223.2 \mathrm{~K}$ and $4.36 \mathrm{MJ} / \mathrm{Kg}$ ) corresponding to $100 \%$ load. The input variable flow rates for coal air and steam are also within the allowable limits corresponding to $100 \%$ load. Similar figures for input and output variables corresponding to $50 \%$ and $0 \%$ loads are shown in Figure 10 to Figure 14.

However the following deviations have been observed during the sinusoidal disturbances:

- Coal and steam flow rates are deviating from the allowable band at $0 \%$ load for coal quality variation in the negative direction.

- Temperatures of syngas are not within the limit for $100 \%$ load when the coal quality is increased to $+18 \%$.

It has been observed that GA based PIDF controller applied to lower order modelling provides better results during all situations as compared to (Dixon et. al., 2002, Simm et. al., 2006, Farag et. al., 2006, Koteeswaran et. al., 2014). 

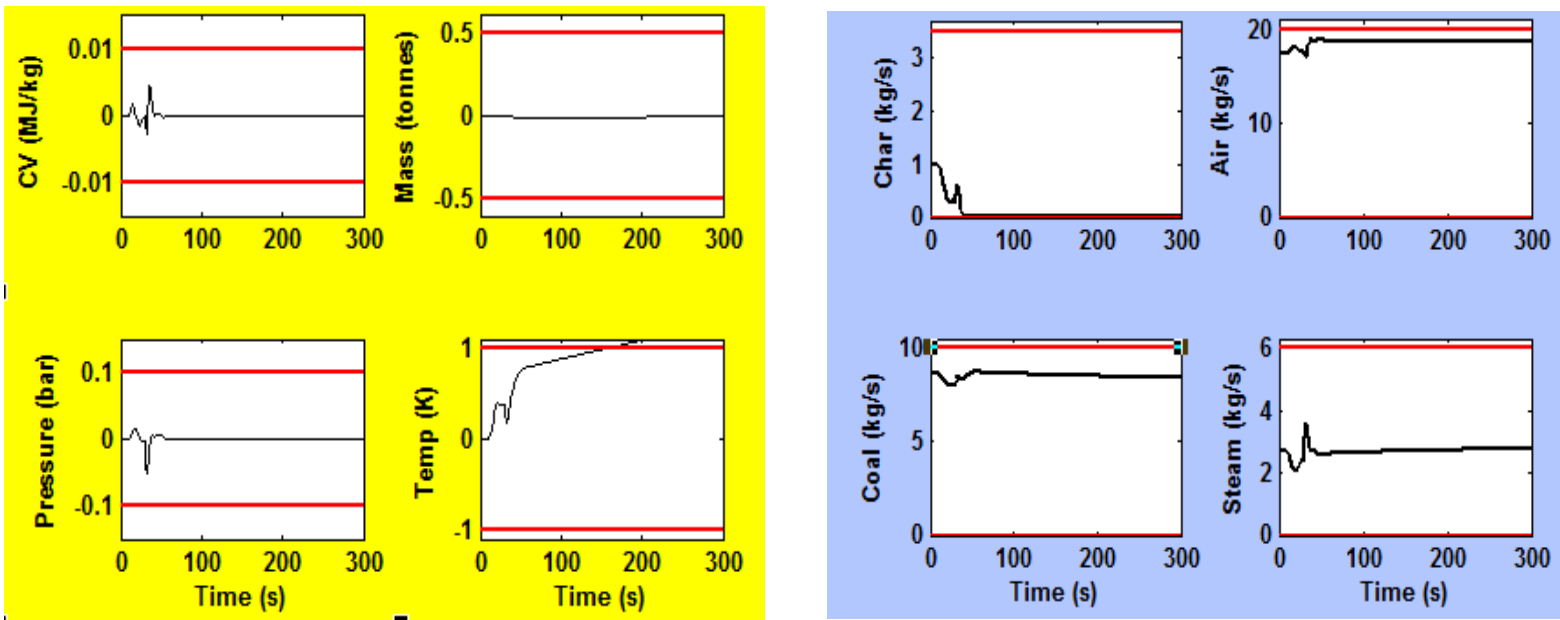

Figure 3. Output and Input response for $+18 \%$ coal quality change with step disturbance for $100 \%$ load
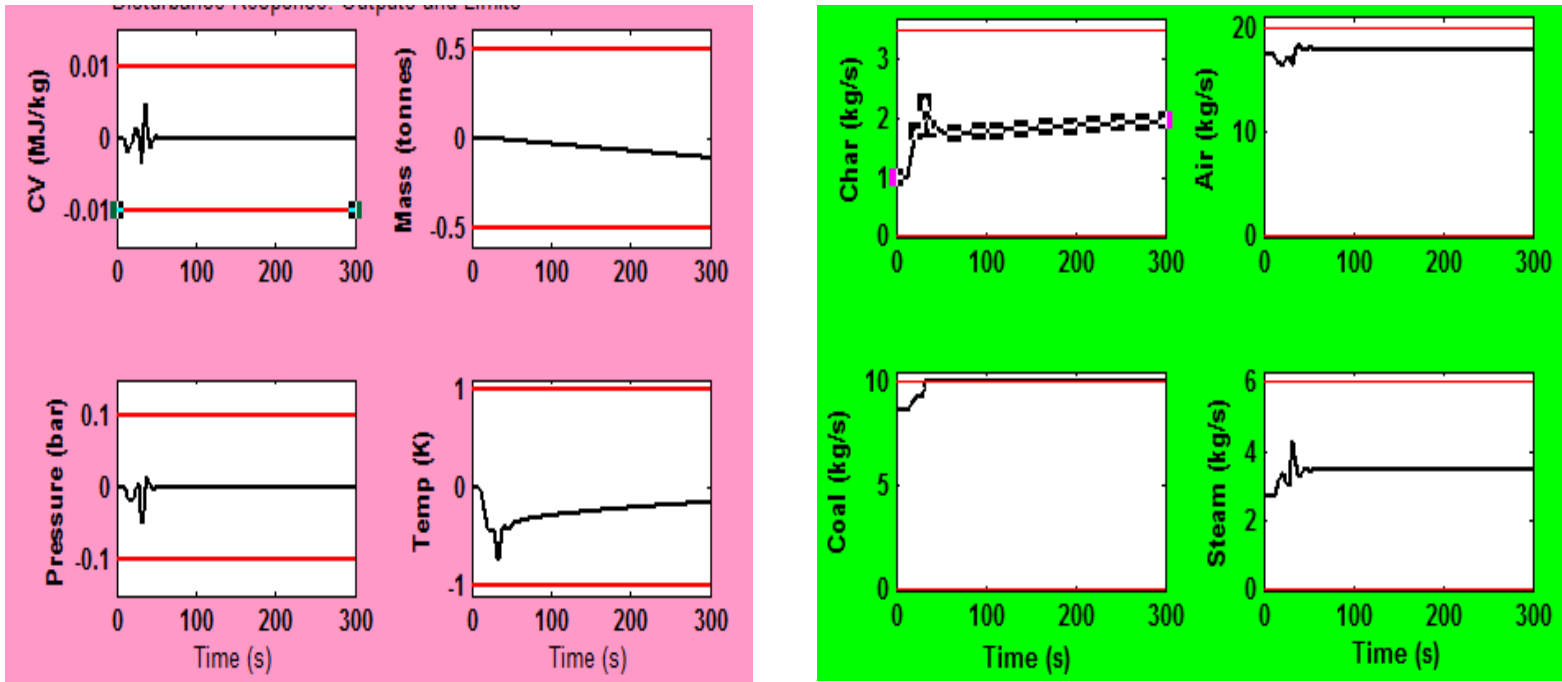

Figure 4. Output and Input response for $-18 \%$ coal quality change with step disturbance for $100 \%$ load
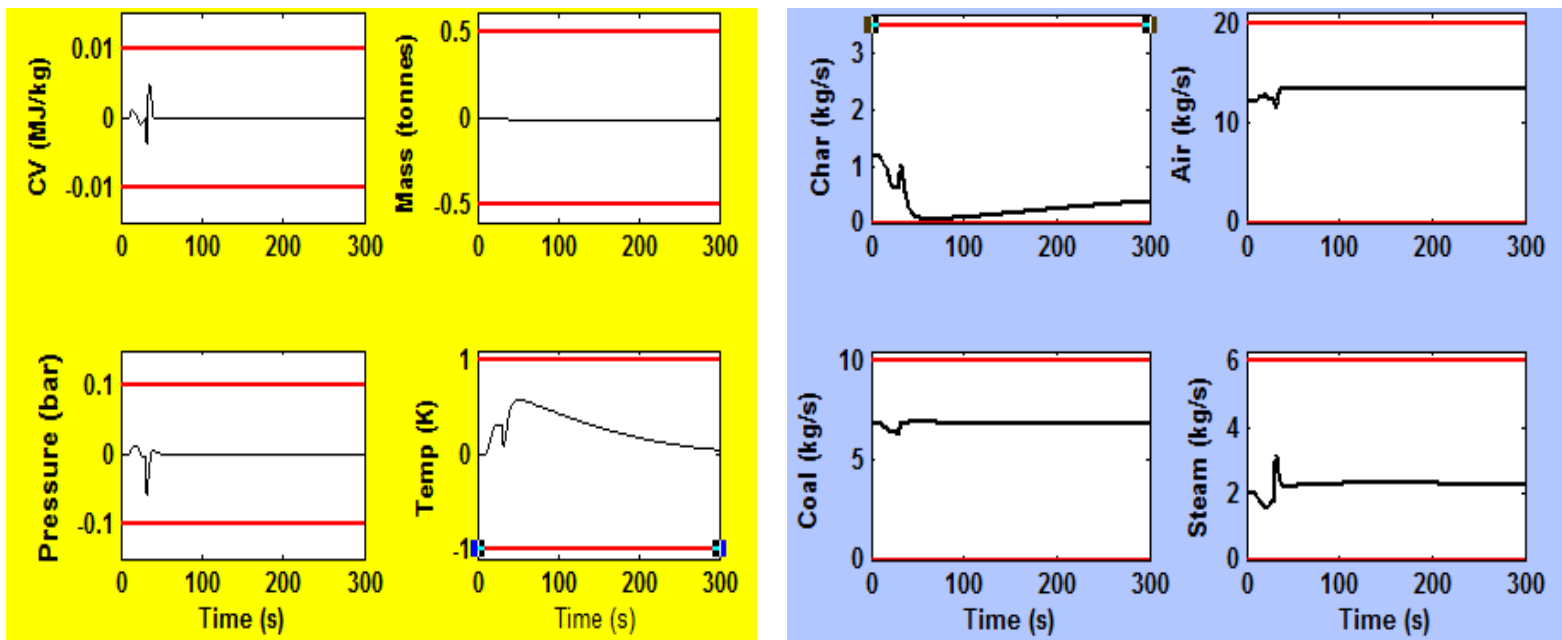

Figure 5. Output and Input response for $+18 \%$ coal quality change with step disturbance for $50 \%$ load 

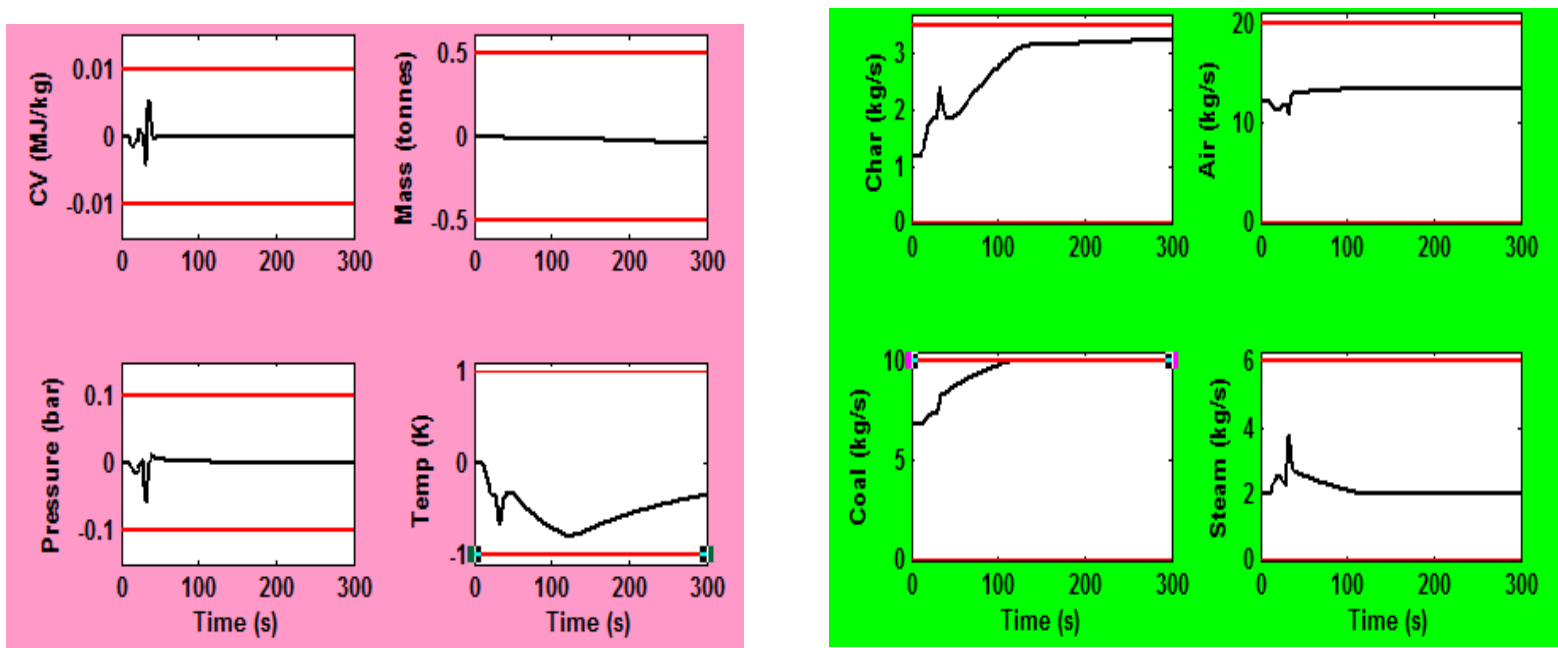

Figure 6. Output and Input response for $-18 \%$ coal quality change with step disturbance for $50 \%$ load
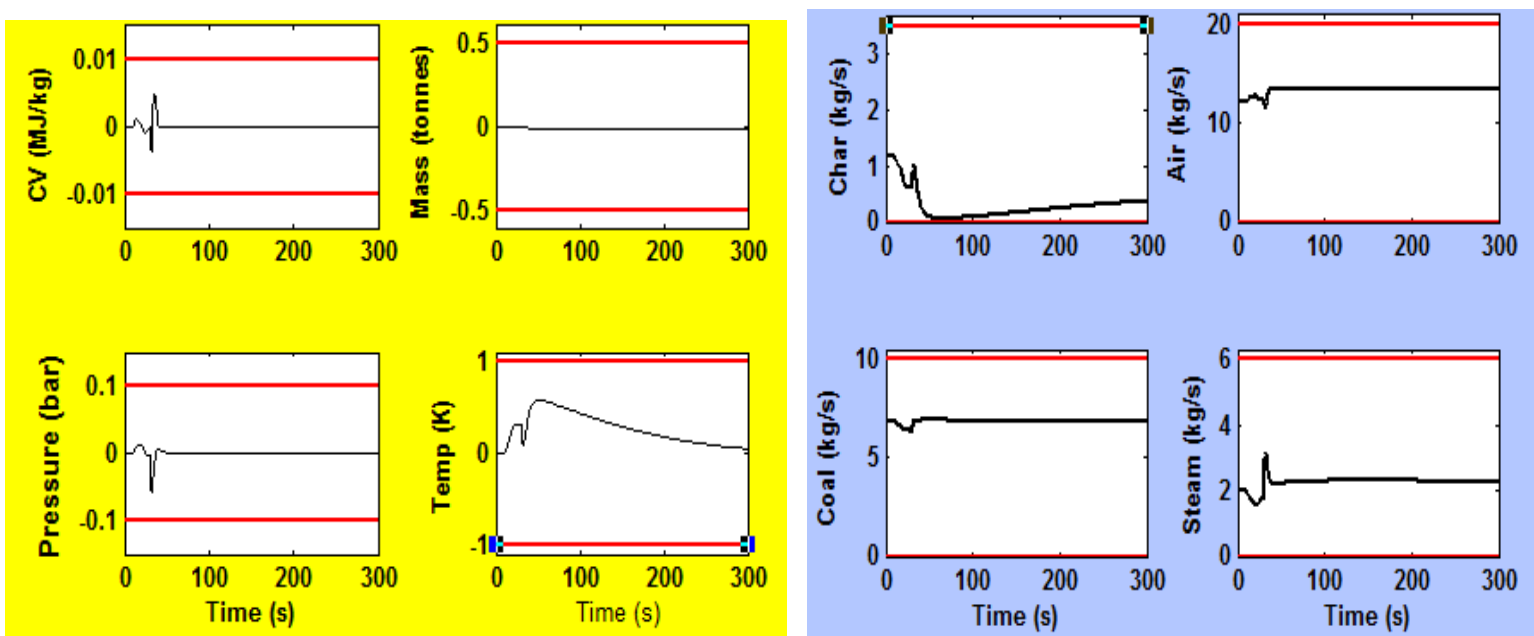

Figure 7. Output and Input response for $+18 \%$ coal quality change with step disturbance for $0 \%$ load
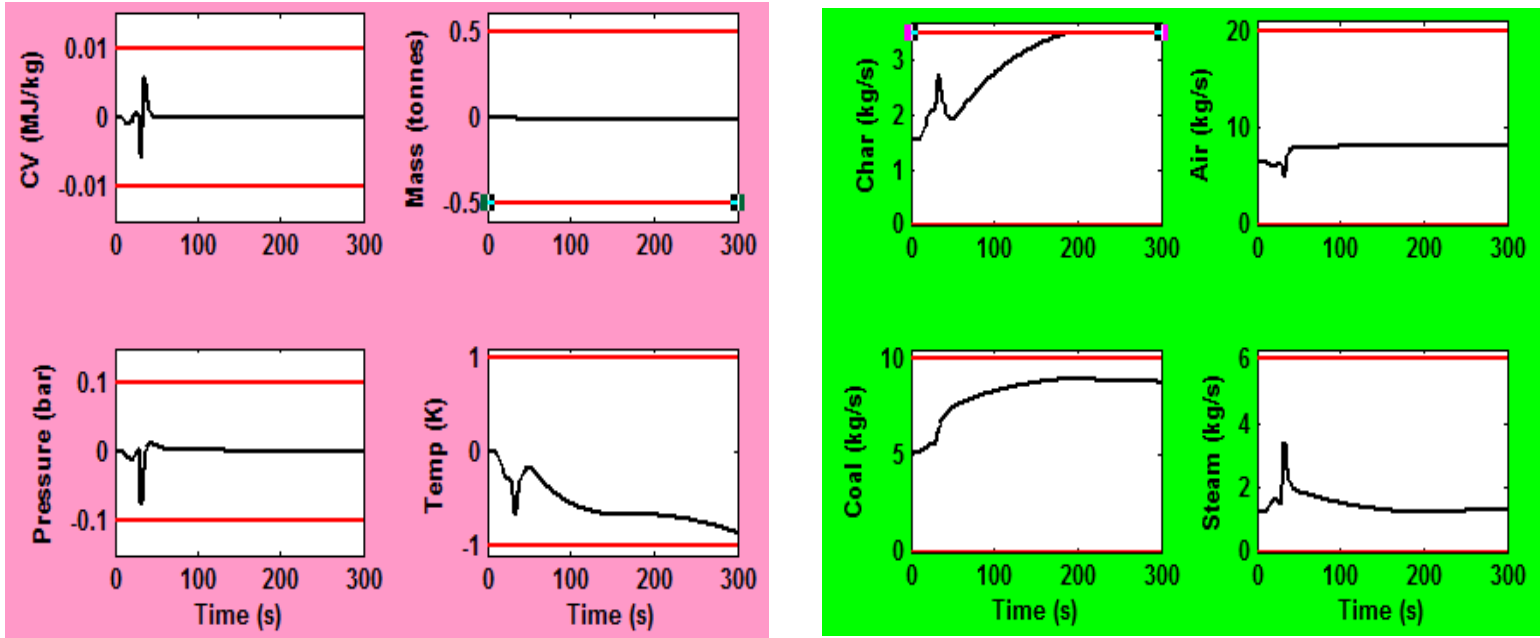

Figure 8 . Output and Input response for $-18 \%$ coal quality change with step disturbance for $0 \%$ load 

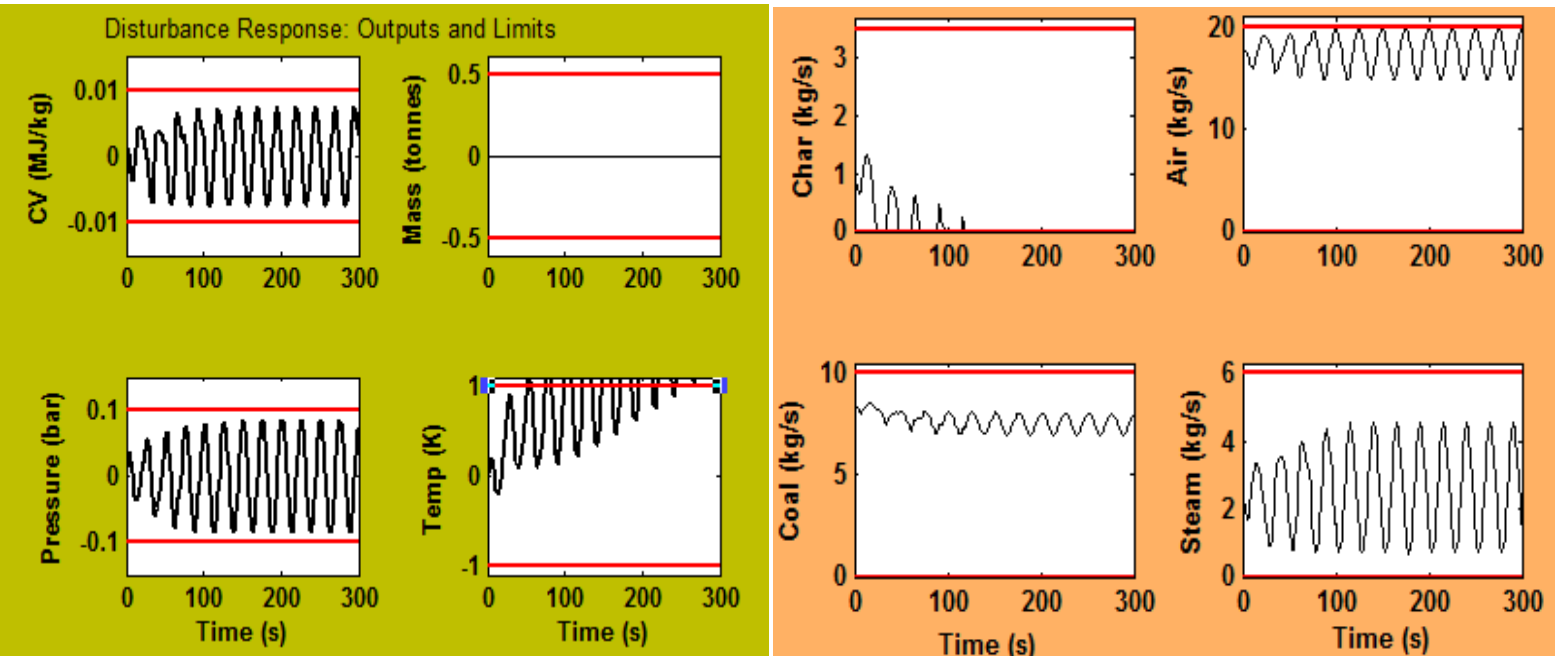

Figure 9. Output and Input response for $+18 \%$ coal quality change with sinusoidal disturbance for $100 \%$ load
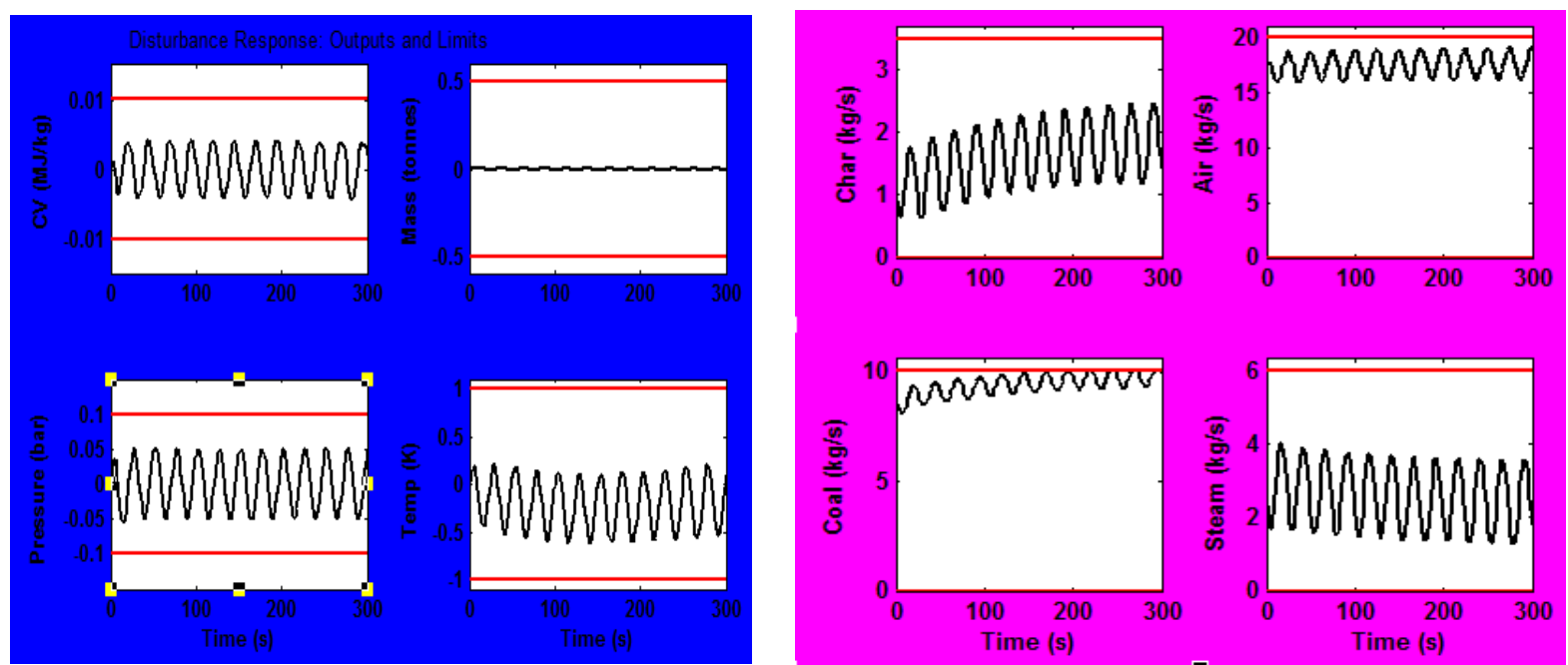

Figure 10. Output and Input response for $-18 \%$ coal quality change with sinusoidal disturbance for $100 \%$ load
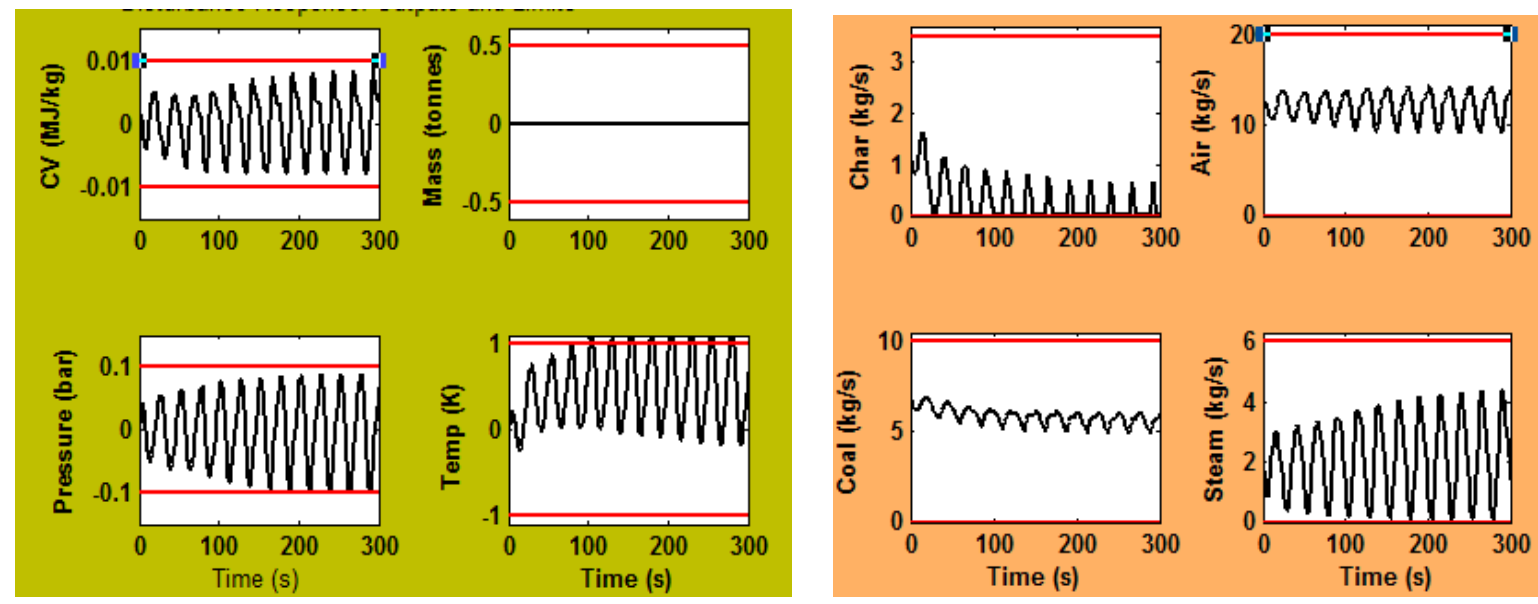

Figure 11 . Output and Input response for $+18 \%$ coal quality change with sinusoidal disturbance for $50 \%$ load 

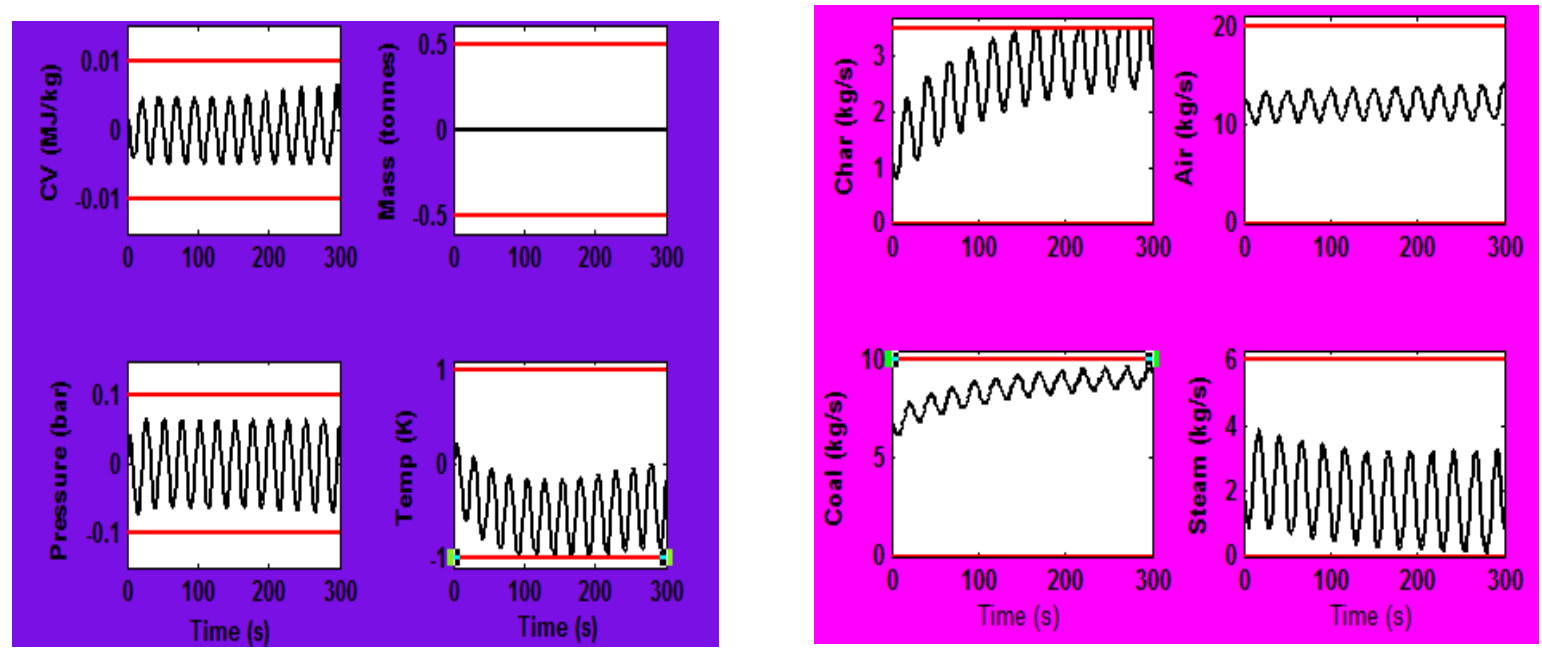

Figure 12. Output and Input response for $-18 \%$ coal quality change with sinusoidal disturbance for $50 \%$ load
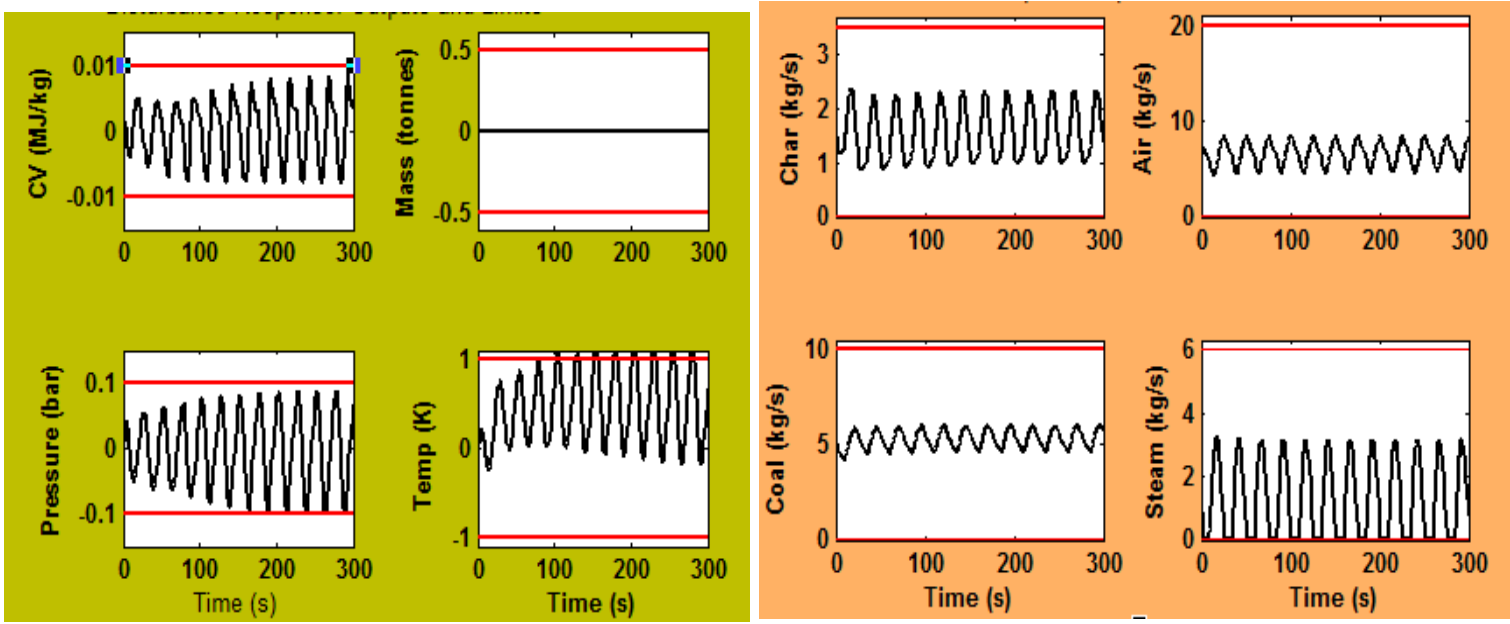

Figure 13 . Output and Input response for $+18 \%$ coal quality change with step disturbance for $0 \%$ load
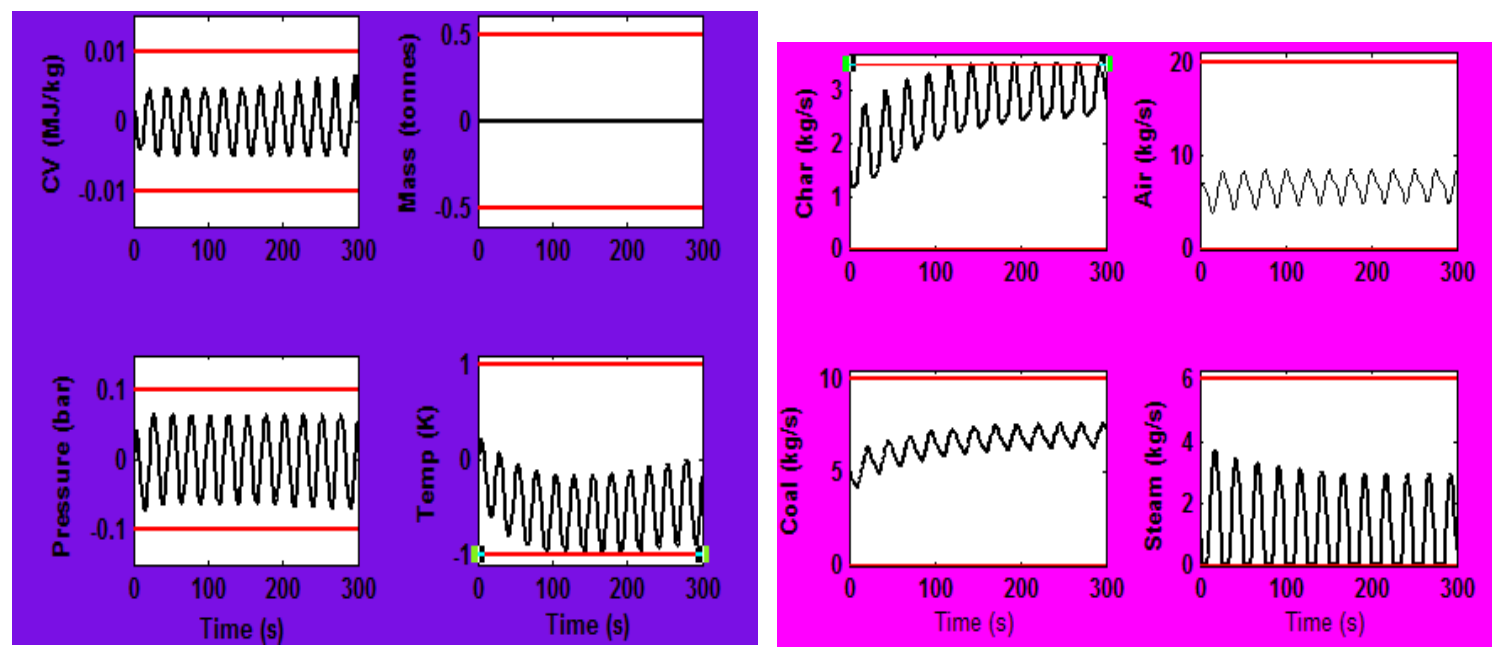

Figure 14. Output and Input response for $-18 \%$ coal quality change with step disturbance for $0 \%$ load 


\section{Conclusion}

Considering the four inputs (char flow rate, coal flow rate, air flow rate and steam flow rate) and four outputs (pressure, temperature, calorific value of syngas and bed mass), an appropriate $4 \times 4$ MIMO model has been formed for gasifier. PID controllers have been augmented with these models and a simulation setup has been made in MATLAB environment for various disturbance analysis. The overshoot and under shoot related to various process parameters such as pressure, temperature and calorific value of syngas (the transient performance requirements of gasifier) are found to be well within the limits during step and sinusoidal variations at Psink (output side) along with coal quality variations for different loads $(0 \%, 50 \%$ and $100 \%)$. The variation and rate of variation of the input variables (manipulated variables) are also found to be well within the specified limits. These results fulfilled the requirement of challenge problem II.

\section{Acknowledgement}

The authors would like to thank Prof. R. Dixon, Lourbourgh university for his support and through email discussions. The authors are grateful to the Management of Karunya University and Sri Krishna College of Engineering and Technology, Coimbatore for their encouragement and support.

\section{References}

Al Seyab, R. K, \& Cao, Y. (2006). Nonlinear model predictive control for the ALSTOM gasifier. Journal of Process Control, 16(8), 795-808. http://dx.doi.org/10.1016/j.jprocont.2006.03.003

Aström, K. J., \& Hägglund, T. (1995). PID Controllers: Theory, Design, and Tuning. Instrument Society of America.

Blasco, F., Xavier, M., Martínez, J., Senent \& Sanchis, J. (2000). Sistemas Automáticos. Editorial U.P.V.

Dixon, R, \& Pik AW. (2006). Alstom Benchmark challenge II on Gasifier control. IEE proceedings- control theory and applications, 153(3), 254-261. http://dx.doi.org/10.1049/ip-cta:20050062

Farag, \& Werner, H. (2006). Structure selection and tuning of multivariable PID controllers for industrial benchmark problem. IEE Proceedings - Control Theory and Applications, 153(3), 262-267. http://dx.doi.org/10.1049/ip-cta:20050061

Gatley, S. L., Bates, D. G., \& Postleth, W. (2004). H infinity control and anti windup compensation of the nonlinear ALSTOM gasifier problem. Proceedings of the institution of Mechanical Engineers, 214, 453-468.

Marlin, T. E. (1995). Process Control. Designing Processes and Control Systems for Dynamic Performance.Mc Graw-Hill.

Kotteeswaran, R., \& Sivakumar, L. (2014). Performance Evaluation of Optimal PI Controller for ALSTOM Gasifier during Coal Quality variations. Journal of Process Control, 24(1), 17-26.

Sivanandam, S. N., \& Deepa, S. N. (2009). A Comparative Study Using Genetic Algorithm and Particle Swarm Optimization for Lower Order System Modelling International Journal of the Computer. The Internet and Management, 17(3), 1-10.

Simm, A., \& Liu, GP. (2006). Improving the performance of the ALSTOM baseline controller using multiobjective optimisation. IEE Proceedings - Control Theory and Applications, 153(3), 286-292. http://dx.doi.org/10.1049/ip-cta:20050131

Xue, Y, Li, D., \& Gao, F, (2010). Multi-objective optimization and selection for the PI control of ALSTOM $\begin{array}{lllll}\text { gasifier problem. } & \text { Control Engineering }\end{array}$ http://dx.doi.org/10.1016/j.conengprac.2009.09.004

Yong, W., \& Junhong, Y. (2009). Study on fuzzy gain scheduled multiple mode predictive control of ALSTOM gasifier problem, Proceeding of 2009 IEEE International conference on Mechatronics and Automation August 9-12 Changchun, china.

\section{Copyrights}

Copyright for this article is retained by the author(s), with first publication rights granted to the journal.

This is an open-access article distributed under the terms and conditions of the Creative Commons Attribution license (http://creativecommons.org/licenses/by/3.0/). 